\title{
Traditional corporate brand marketing communication strategy in the new media era
}

\author{
Wang Li \\ Xijing University, Shaanxi, China
}

Keywords: Brand communication, problem exploration, new media era, marketing strategy

Abstract: With the development and maturity of the market economy, China's market competition has become increasingly fierce, and the brand has become a powerful and powerful tool for enterprises to enhance their own market competitiveness. A well-known and reputable brand can not only increase the appeal of products to consumers, but also help to stand out from the numerous products on the market, increase consumer loyalty to products, and drive a wider range of potential consumer groups. The rapid development of new media technologies in the current era, high coverage, and huge increments has gradually shown their great power in communication. It divides the audience's attention with an infinite number of communication themes and massive content. It lowers the threshold for communication and breaks down and complicates the simplicity of the traditional media environment. Then you need to establish independent brands, cultivate and manage brands, promote product sales, increase market share, and gain a dominant position in market competition. Therefore, studying brand communication is of great significance to the development of enterprises.

\section{Introduction}

Brand communication is a process of enhancing the brand effect. Through various means, it continuously realizes the communication between the brand and the target audience, and optimizes the process of brand equity. At the same time, new media technology has developed rapidly in the current era, with high coverage and huge increments, and it has gradually shown its great power in communication. By establishing independent brands, cultivating and managing brands, promoting product sales, and increasing market share, companies can gain a dominant position in market competition.

\section{Brand and brand communication of traditional enterprises}

\subsection{Brand establishment of traditional enterprises}

Brand is the bridge between products, symbols, people, business and consumers. It is a comprehensive framework, which is a kind of recognition and dependence of consumers on products, and consumers and products are built deeper ${ }^{[1]}$. Brand is the external expression and value of the intrinsic property of the enterprise, and the brand becomes a way to integrate different 
resources of the enterprise. In today's era, it is an era of brand consumption. One of the key factors that win the support of consumers to determine the success of a product is to realize the value re-creation of the product through the brand and create more profits for the enterprise.

\subsection{Brand Communication of Traditional Enterprises}

In the new media, the marketing communication of enterprises is not simply advertising, public relations, but a holistic issue. However, in China, many companies do not understand it, and they do not realize its impact on the marketing communication and opportunities. New media not only diversifies the way companies promote their brands, but also reduces the cost of marketing. For example, in the past, many companies thought that they would spend a lot of money to build an official website, publish corporate news and product information on a regular or irregular basis, and constantly build new websites and promotions, but the results are often not ideal. The new media offers more free open platforms and resource sharing.

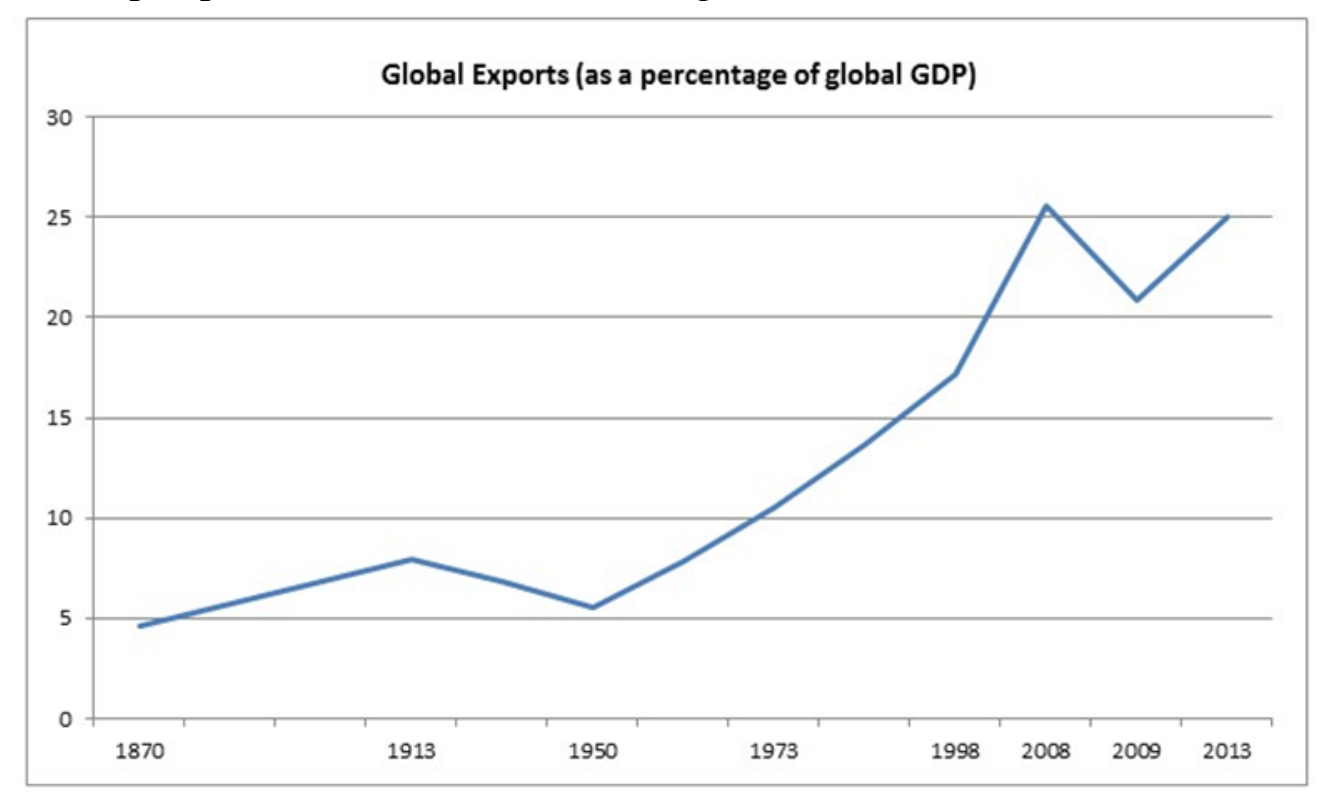

Fig 1 World trade has yet to recover to pre-financial tsunami levels

Brand communication is a process of enhancing the brand effect. Through various means, it continuously realizes the communication between the brand and the target audience, and optimizes the process of brand equity. Based on the core value of the brand, the company uses the overall framework of brand recognition, using advertising, public relations, interpersonal communication and various media resources to achieve the promotion of specific brands, establish brand image, and promote market sales methods and means. For example, to establish an official account in Kaixin.com, establish an interest group in Douban, establish brand space in Tianya, establish an official Weibo on Sina Weibo, build brand entries in Baidu Encyclopedia, and build fan groups on $\mathrm{QQ}$, on their official website. Create interactive prize-winning games; basically these are free ${ }^{[2]}$.

\subsection{The necessity of brand communication}

Brand communication promotes the sales of enterprise products. It is an effective means for enterprises to meet consumer needs and cultivate consumer loyalty. It is also an important part of brand culture. Through the effective dissemination of the brand, the popularity of the product can be expanded, and the product reputation can be quickly established, which is recognized by the 
consumers and the public, enabling the brand to develop at a high speed. At the same time, the effective dissemination of the brand is strong for the brand to occupy the market and expand the market. The strong propaganda foundation can realize the effective connection between the brand and the target market; brand communication is a way of product transformation. Through communication, the product gets the consumer's understanding, and the characteristics of the product are quickly recognized through product communication. Products are quickly promoted and sold ${ }^{[1]}$.

\subsection{Characteristics of brand communication}

\subsubsection{Aggregation of information}

In the process of specific operation brand communication, brand communicators need to use the market analysis and product characteristics to conduct dialectical information selection. The process of communication is a process of information processing and information integration, so that the brand information that is transmitted is "combined". There is a foundation, and "poly" can express God.

\subsubsection{Target of the audience}

For brand communicators, the important mission is to find the target audience. Once the target consumers and brand followers are identified, the brand communicators need specific media to launch an active attack and start targeted promotion. The effect of communication can be achieved.

Table 1 Cranach $\alpha$ coefficient of the degree of conformity of the enterprise

\begin{tabular}{|c|c|c|}
\hline & Cranach, s & \\
\hline Cranach, s & Alpha Based & \\
\hline Alpha & On & \\
\hline & Standardized & N of \\
\hline 0.708 & Items & 25 \\
\hline
\end{tabular}

\subsubsection{The diversity of the media}

Diversification and diversification of the media approach, for consumers and audiences, can accept traditional media, such as newspapers, magazines, television, radio, street signs, posters, DM, car body, light boxes, etc. Constantly adapt to the new media approach, through the combination of new and old media, can better achieve the effect of propaganda and communication ${ }^{[1]}$.

\section{Some problems in the spread of corporate brand}

\section{1 brand communication channels are relatively single}

First of all, some enterprises are too narrow in the selection of brand communication media, but only pay attention to the role of traditional media, for example: only through the domestic plastic journals or the network to carry out some latest news release. There is no specific planning and thinking about the specific application of new media.

Secondly, some enterprises are too one-sided in the positioning of brand communication. Some enterprises carry out so-called global promotion, but they only value foreign markets, neglect the promotion of domestic market brands, resulting in weak brand foundation. In order to eliminate the 
influence due to the difference in the magnitude of the cardinality, the coefficient of variation is the sample standard deviation divided by the sample mean, which is calculated as:

$$
C V=\frac{\sigma}{\bar{X}}, \sigma=\sqrt{\sum_{i=1}^{n} \frac{\left(x_{i}-\bar{x}\right)^{2}}{n}}
$$

Where $\mathrm{n}$ is the number of samples, $\mathrm{xi}$ is the sample value of the $\mathrm{i}$ region, and represents the average value of the sample, indicating the standard deviation. This indicator uses the data of all regions, so the amount of information contained is sufficient. In practice, the weighted coefficient of variation is also commonly used as the Wilson coefficient [8]. Its formula is:

$$
V u=\frac{1}{x^{\prime}} \times \sqrt{\sum_{i=1}^{\mathrm{n}} \frac{\left(x_{i}-x\right)^{2} p_{\mathrm{i}}}{p}}
$$

Finally, there is a lack of short-term training within the company. Training enhances communication between employers and employees, employees and suppliers. Training is also an important way to improve product familiarity. Through training to increase employees' understanding of products, we can better disseminate products.

\subsection{Insufficient continuity of brand communication}

Some enterprises have less investment in the construction and dissemination of market brands, lack of continuity, and lack of stamina in the confrontation of competitors. The various brand resources of the enterprise have not been effectively integrated, the communication methods and channels lack systematic management, and the brand promotion lacks overall planning, resulting in low transmission efficiency and ineffective results. The brand awareness is weak, and the lack of brand management personnel and organizations has led to the emergence of "nobody care" in the post-brand communication ${ }^{[3]}$.

\subsection{Brand communication is weak}

Communication is the link between brands and consumers. Communication is an important means for consumers to recognize brands. Communication has established the brand's popularity and spread the brand image. In the strategic environment of brand communication, brands are increasingly becoming an important factor influencing consumers' purchasing choices. Therefore, from a multi-faceted, multi-angle, multi-faceted to comprehensively plan the strategy and tactics of brand integrated marketing communication, establish a three-dimensional communication mode, make full use of the communication characteristics of new and old media, and establish a multi-level communication media. At present, enterprises have weak communication in the process of communication, limited coverage of communication, and a short duration of transmission.

\section{Conclusions}

In the context of new media technologies, corporate marketing communication is not simply advertising, public relations, but a holistic issue. However, in China, many companies do not understand it, and they do not realize its impact on the marketing communication and opportunities. New media not only diversifies the way companies promote their brands, but also reduces the cost of marketing. Brand communication promotes the sales of enterprise products. It is an effective 
means for enterprises to meet consumer needs and cultivate consumer loyalty. It is also an important part of brand culture.

\section{References}

[1] Grohmann A G B. Can good news be bad? The role of brand communication strategy and brand commitment in the announcement of product improvements [J]. Journal of Marketing Communications, 2017, 20(5):352-365.

[2] Vasylivna I N. Formation of brand-focused communication management system of industrial enterprise [J]. Marketing İ Menedžment Innovacìj, 2016, 5(4).

[3] Olga Juraskova, Martina Jurikova, Romana Cockova. Influence of Marketing Communication Tools on Brand Building in the Context of Marketing Management and Corporate Prosperity [J]. 2017.

[4] Meng X. Brand Marketing of Agricultural Products and the Strategy of Integrated Marketing Communication [J]. Academic Periodical of Farm Products Processing, 2017.

[5] Chen H L, Lai X F, University Y. On Strategies of Brand Marketing and Communication in New Media Era [J]. Journal of Wuhan Commercial Service College, 2013.

[6] Omar M, Jr R L W, Lingelbach D. Global brand market-entry strategy to manage corporate reputation [J]. Journal of Product \& Brand Management, 2014, 18(3):177-187. 